\title{
Diffuse malignant pleural mesothelioma and asbestos exposure
}

\author{
F. WHITWELL and RACHEL M. RAWCLIFFE \\ Broadgreen Hospital, Liverpool ; Aintree Hospital, Liverpool ; and St. Catherine's Hospital, Birkenhead
}

Pleural mesothelioma has been diagnosed in 52 patients in three hospitals on Merseyside between 1955 and 1970, 60\% being diagnosed from operation specimens and the rest from postmortem tissues. Necropsies eventually held on nearly half the operation cases confirmed the diagnosis, giving a necropsy rate of $70 \%$ for the series. The morbid anatomy conformed to earlier descriptions except that widespread metastases were much commoner than has usually been described. Histological findings agreed with previous accounts of the tumour, except that, in our hands, special acid mucopolysaccharide staining was less reliable than Southgate's mucicarmine, which was of value in differential diagnosis. Association with asbestos was confirmed from industrial histories in $80 \%$ of cases, the commonest industries involved being shipbuilding and repairing in men and sackware repairing in women. Lungs of industrial mesothelioma cases showed basal asbestosis in $17 \%$ and excessive asbestos bodies in almost all the rest. Quantitative comparison of asbestos bodies in lung smears from mesothelioma cases compared with lung smears from other Merseyside adults showed much higher counts in the mesothelioma cases. The interval from first exposure to asbestos until appearance of mesothelioma ranged between 13 and 63 years, with a mean of 42 years. We think the incidence of mesothelioma will continue to rise with the increased use of asbestos until about 40 years after adequate protective measures have been taken.

The recent reinstatement of diffuse malignant pleural mesothelioma as a legitimate neoplasm dates mainly from the papers of Godwin in 1957 and McCaughey in 1958. However, the controversy as to whether these pleural tumours are primary or almost always secondary might have remained a nice academic exercise but for the work of Wagner, Sleggs, and Marchand who in 1960 reported an association of pleural mesothelioma with asbestos exposure. They described 33 pleural mesotheliomas associated with asbestos exposure in Cape Province, the exposure being more frequently environmental than occupational.

Since then there have been many studies linking both pleural and peritoneal mesotheliomas with asbestos. In the United Kingdom the largest series of cases published have occurred in East London, usually in people working in or living near asbestos factories (Enticknap and Smither, 1964 ; Hourihane, 1964 ; Newhouse and Thompson, 1965), and other accounts have described cases occurring in the major shipbuilding areas. The Belfast cases described by McCaughey in 1958 were reviewed in 1965 with further cases added, showing asbestos exposure in 32 out of 42 cases (Elmes, McCaughey, and Wade, 1965). In 1964 Owen reported 17 cases of mesothelioma on Merseyside with an asbestos link in $82 \%$ of cases, and in 1968 Harries analysed the trades at risk in the Royal Naval dockyards.

These investigations have been largely retrospective, often involving much environmental and occupational research made after the patients' deaths, and also hampered by an inadequacy of preserved specimens, particularly lung tissue, making assessment of the asbestos association very difficult, which may as a result have been underestimated. The present paper is a prospective continuation of the Merseyside series reported by Owen in 1964, when he described cases occurring between 1955 and 1963 in what was also largely a retrospective study.

\section{THE SUBJECTS STUDIED}

Fifty-two cases have been examined, comprising 14 of the 17 cases described by Owen (1964) and 38 addi- $\overrightarrow{\mathbb{D}}$ tional cases which have occurred between 1963 and $\frac{\rho}{\mathbb{D}}$ 1970. The three cases of the earlier series not included $\varrho$ are one which was a peritoneal tumour, one for which $\bar{x}$ there were no histological sections, and one (his case 
14) for which the records and slides have been lost.

All but one patient, who was in the earlier series, have been patients in Broadgreen Hospital or Aintree Hospital, Liverpool, or in St. Catherine's Hospital, Birkenhead. These three hospitals admit the majority of Merseyside pleural mesotheliomas, because patients are referred to the Regional Thoracic Surgical Centres at Broadgreen and Aintree Hospitals, while St. Catherine's Hospital is the district hospital for most of those who work in Birkenhead shipyards. Though all the cases were diagnosed in these hospitals a few died in other hospitals where necropsies were sometimes performed. Tumour tissue and necropsy reports were available for study in these cases, though sometimes no lung tissue was examined microscopically.

\section{HISTOLOGICAL EXAMINATION IN NECROPSY CASES}

The following routine has been adopted in the three hospitals for the last 24 cases, being performed by ourselves in 18 cases.

THE TUMOUR Several tissue blocks from the primary and its direct extensions, and blocks from any secondaries, were examined microscopically in each case. Sections were stained routinely with haematoxylin and eosin, Southgate's mucicarmine, and alcian blue. In the earlier cases, in order to demonstrate hyaluronic acid (Wagner, Munday, and Harington, 1962), Hale's colloidal iron, alcian blue, Southgate's mucicarmine, and periodic acid Schiff were used on hyaluronidasetreated and untreated sections, but the method was abandoned as the results were inconclusive, possibly due to formol-saline fixation.

THE LUNGS The lungs were examined for fine fibrosis, honeycomb areas, and scarred areas. Blocks were examined from any such areas but also from the bases of a lower lobe when the lung tissue looked normal. In addition $20 \mu$ thick unstained sections from the base of a lower lobe were examined for asbestos bodies.

LUNG JUICE SMEARS Asbestos bodies are more readily demonstrated by examining smears of lung juice than by examining lung sections. The same method of lung juice preparation was used throughout this study and also in a series of 200 consecutive adult necropsies at Broadgreen Hospital in 1966-7. The method is not as searching as many that have been described but seems to have about the same sensitivity as the techniques used by Roberts (1967) in Glasgow, and Ashcroft (1968) on Tyneside. It does provide a comparison of the lung asbestos body content of the urban population of Merseyside with that of the mesothelioma patients.

At necropsy a basal segment of lower lobe is removed and cut into several pieces, which are squeezed hard over a beaker, into which the fluid collects. Enough water is added to the juice to haemolyse the red cells, though this is unnecessary when pulmonary oedema is present. The beaker is left at room temperature for a day, when the contents are transferred to a conical centrifuge tube. After spinning the tube the supernatant is discarded and smears of the deposit are spread on a microscope slide. The dried smear is mounted in balsam and examined with a 2/3 in objective. Quick identification of asbestos bodies can be aided by staining with Perls' stain, but the intense blue staining sometimes makes it difficult to differentiate true from pseudo asbestos bodies, as the centre of the body becomes obscured, so unstained smears are preferred.

This method of preparing smears can be used quite satisfactorily with lungs which have been fixed for several years.

\section{DIAGNOSIS}

The diagnosis has always been made from histological findings, obtained during the patients' lives in $60 \%$ of cases and at necropsy examination in the rest.

Only rarely was it possible to make a definite diagnosis from a needle biopsy specimen, and most tissues were obtained at thoracotomy when pleural biopsy, pleurectomy, decortication, and occasionally pleuro-pneumonectomy was performed. The same staining methods were used with operation specimens as with the postmortem tissues. Positive diagnosis was made in 30 patients, confirmed eventually at necropsy in 14 cases. Eleven patients have died without necropsy studies, and five are still alive who have been diagnosed in the last three years. It was possible to find asbestos bodies in only four of these surgical specimens, which usually showed just narrow rims of subpleural alveoli, or consisted only of parietal pleura. In 22 cases the diagnosis was first confirmed at necropsy, though often it had been suspected clinically for months or even years. In scven of these cases there had been negative pleural needle biopsies.

\section{HISTOLOGICAL FEATURES}

The wide range of microscopical features reported by many writers and well described and illustrated by Godwin (1957), McCaughey (1958), and Hourihane (1964) were present in this series. Though some admixture of types was found in most cases, the tumours were predominantly of one form in over half the cases. They were classified as follows:

$\begin{array}{lr}\text { Tubulo-papillary } & 20 \text { cases } \\ \text { Sarcomatous } & 11 \text { cases } \\ \text { Undifferentiated polygonal } & 3 \text { cases } \\ \text { Mixed } & 18 \text { cases }\end{array}$


Tumour giant-cells were sometimes present in the sarcomatous, polygonal, and mixed types.

TUBULO-PAPILLARY TYPE These tumours can often only with difficulty be differentiated from secondary adenocarcinomas, particularly those originating from primaries in the lung, prostate, stomach, breast, and ovary.

The following features are seen in most mesotheliomas of this type and are much less commonly found in secondary carcinomas:

1. Tumour cells are regular in size and arranged in an orderly pattern. The nuclei are vesicular and regular, seldom showing mitotic activity, though there are exceptions to this last point.

2. The branching acini are lined by low columnar or cuboidal cells, which in some places are so flattened that the acini look more like empty hyperplastic blood capillaries than glandular acini (Fig. 1).

3. The acinar cells and lumina rarely contain any secretion which stains brightly with Southgate's mucicarmine, like epithelial mucin, though there is often secretion in the acini and within lining cells which stains vigorously with alcian blue.
4. Dilated acini often contain and may be distended by branching papillary fronds of tumour cells, which arise from acinar lining cells and cover a fine connective tissue core (Fig. 2). This feature is also seen in secondary ovarian carcinoma but otherwise suggests a mesothelioma.

5. Where tumour has invaded lung or lymph node the mesothelial tumour cells occasionally are seen to contain dust or carbon particles in their cytoplasm (Fig. 3), which is very rarely seen with carcinoma cells.

SARCOMATOUS TYPE (Figs 4 and 5) A wide range of appearances from cellular fasciculated fibrosarcoma through myxoma to large areas of relatively acellular collagen may be found, but nuclei are usually regular and mitoses infrequent. There may be so much collagen and so little cellular tumour present that it is easy to mistake the pleural thickening for the plaques associated with asbestosis. In two cases only collagen was found in the tumour tissue encasing the lung, but where the tumour had extended through the pericardium into the heart and through the diaphragm into the liver, these organs showed typical fibrosarcoma.

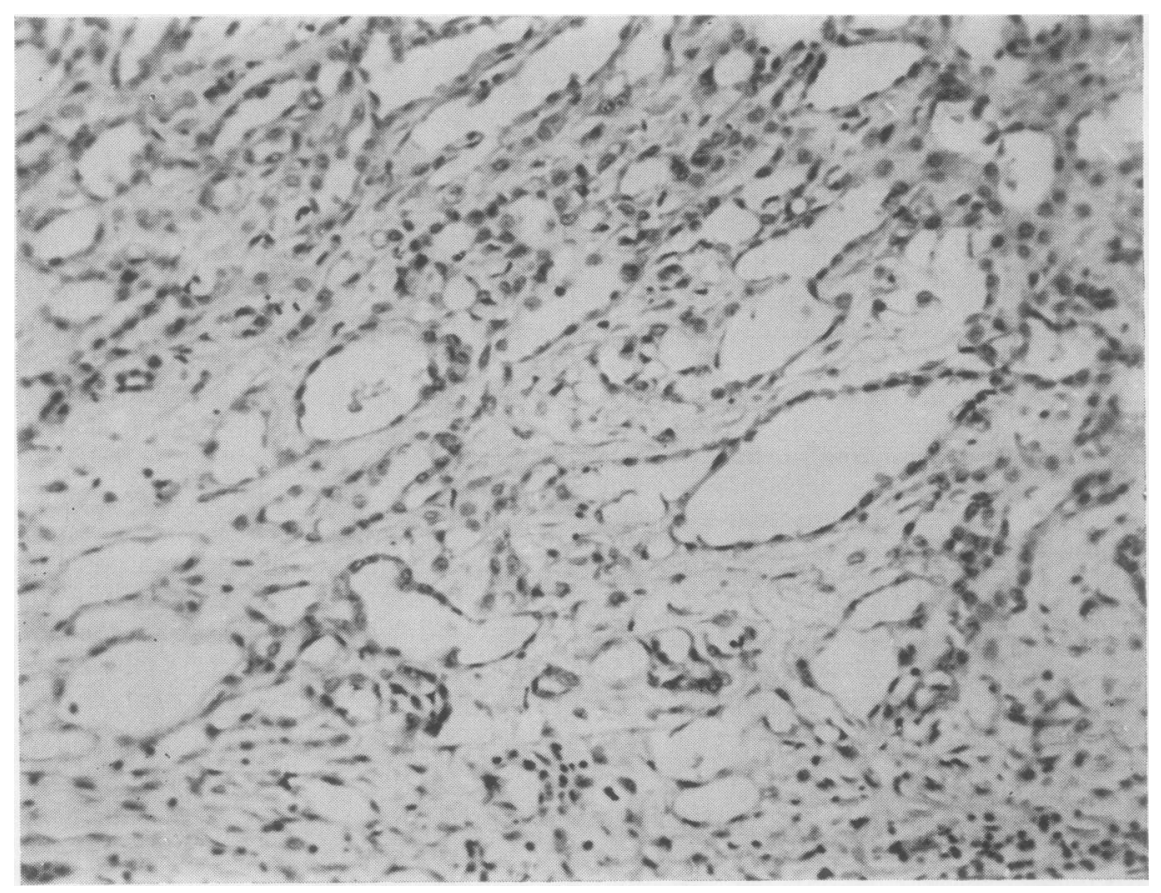

FIG. 1. Capillary pattern in tubulo-papillary tumour. Haematoxylin and eosin $\times 165$. 


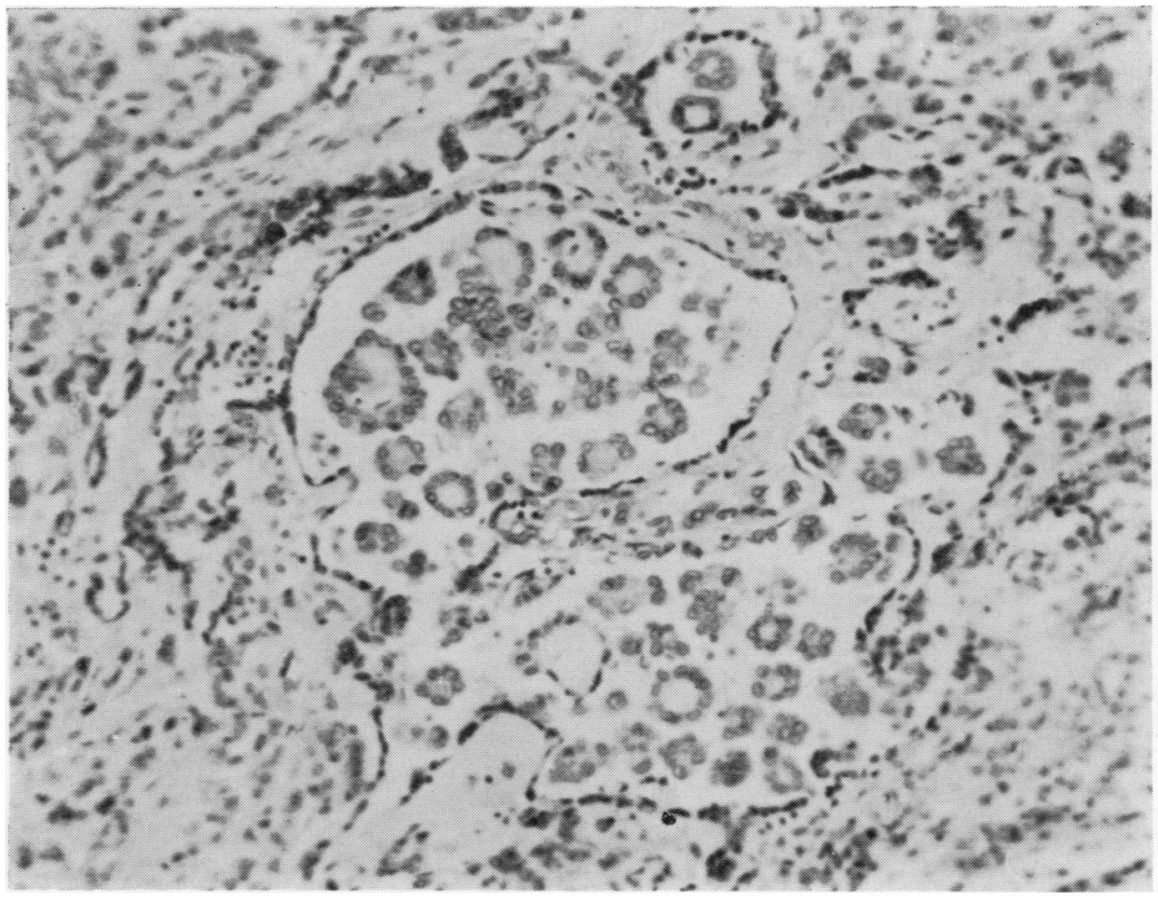

FIG. 2. Papillary fronds in acini of tubulo-papillary tumour. Haematoxylin and eosin $\times 165$.

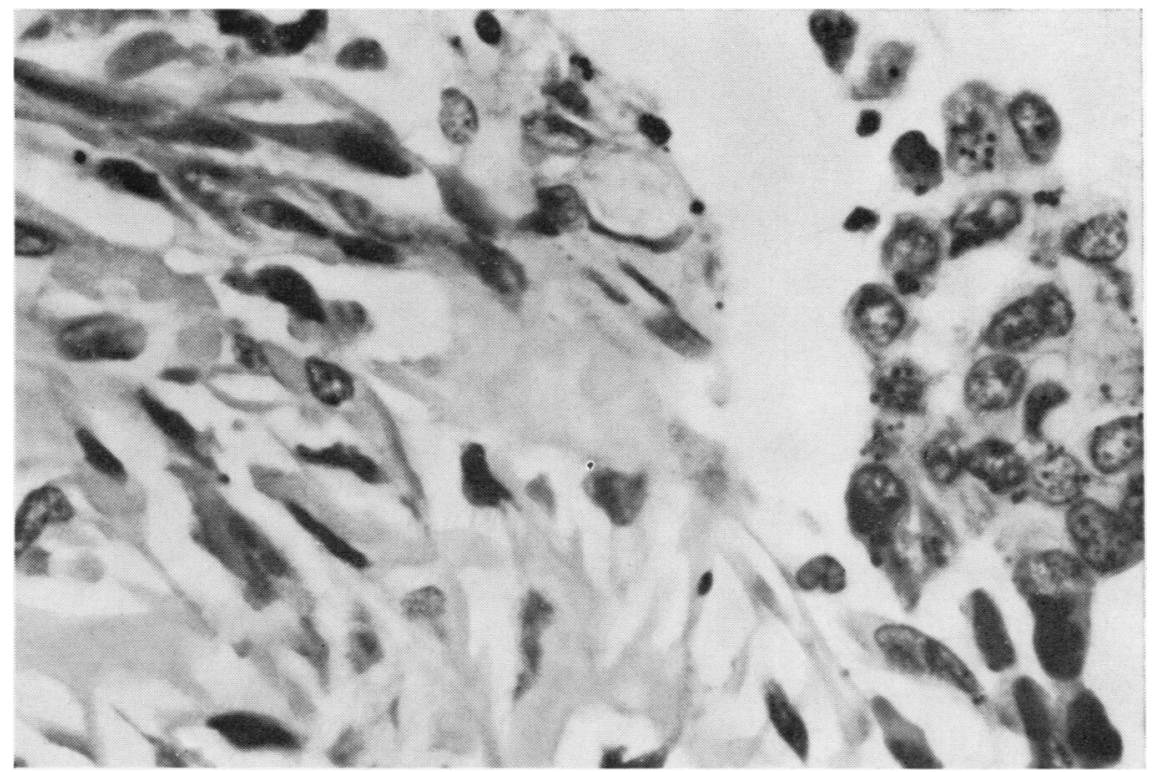

FIG. 3. Dust particles in cytoplasm of mixed tumour. Haematoxylin and eosin $\times 900$. 


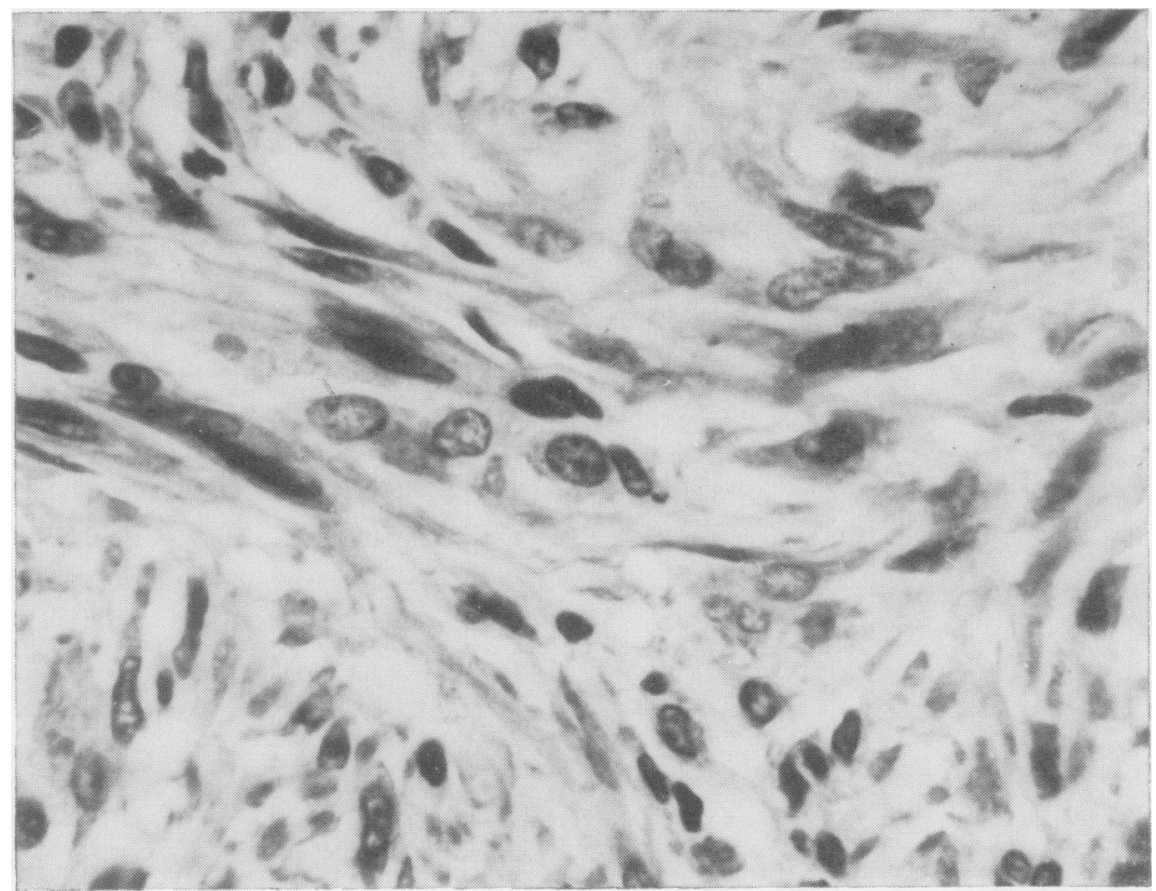

FIG. 4. Cellular fibrosarcoma. Haematoxylin and eosin $\times 785$.

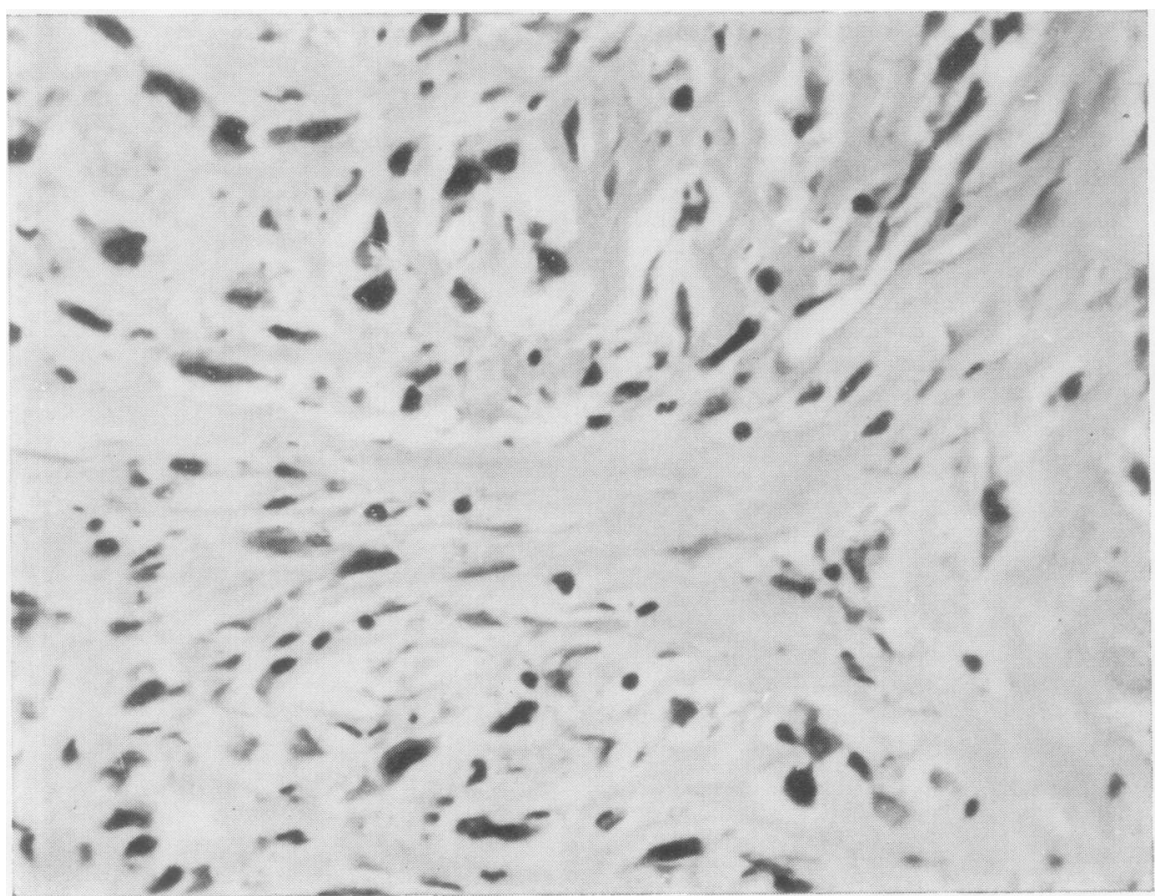

FIG. 5. Collagenous fibrosarcoma. Haematoxylin and eosin $\times 385$. 
The tumour must be differentiated from fibrosarcoma of the lung and from secondary fibrosarcoma. However, apart from uterine fibromyosarcomas, the primary sources of secondary fibrosarcomas are usually clinically obvious.

UNDIFFERENTIATED POLYGONAL TYPE Tissue of this type is present in many tumours, but at times it occurs in an unmixed form, when it has been described as sheet-like, polygonal, or solid epithelial. In this series it was found in a pure form in three cases, but large areas of this type of tumour were present in six other cases. The tissue shows a uniform pattern of regular cells which have abundant eosinophilic cytoplasm (Fig. 6). When the tumour cells are compressed together their cell membranes produce a polygonal or honeycomb outline like pavement epithelium, but where the cells are separated by tissue fluid the cell outlines become rounded. Occasionally these cells form tumour giant-cells, but mitoses are uncommon.

These sheets of cells look remarkably benign in most cases, and the problem is less one of differentiating the lesion from carcinoma than of distinguishing it from benign reactive hyperplasia of the pleura (such as occurs over old pulmonary infarcts), though this difficulty arises only with biopsy material.
Very occasionally there occurs a much more malignant-looking variant of this type, with nuclear and cytoplasmic irregularities, mitoses, and tumour giant-cells, which it is difficult to distinguish from carcinoma.

MIXED TYPE (Figs 7 to 13, all taken from one case to illustrate the wide range of features.) The mixed tumour is one of the commonest, and is the easiest to diagnose when adequate tissue is available. With this type of tumour there may be large areas where only one histological pattern is seen, so many sections must be examined, but in a fortunately chosen area not only is there a mixture of tubulo-papillary, sarcomatous, and polygonal elements but the tumour cells show all stages of transition between these types. The features described as characteristic of the previous types are equally well seen in the mixed types.

In mixed tumours it is quite common to find that only one tumour element is present in some of the metastases. Usually this seems a matter of chance but the tubulo-papillary elements occur by themselves in affected lymph nodes, and only the sarcomatous elements have been found in bony secondaries.

Many tubulo-papillary tumours are associated with a dense deposition of relatively acellular collagen, either a stromal response to the tumour

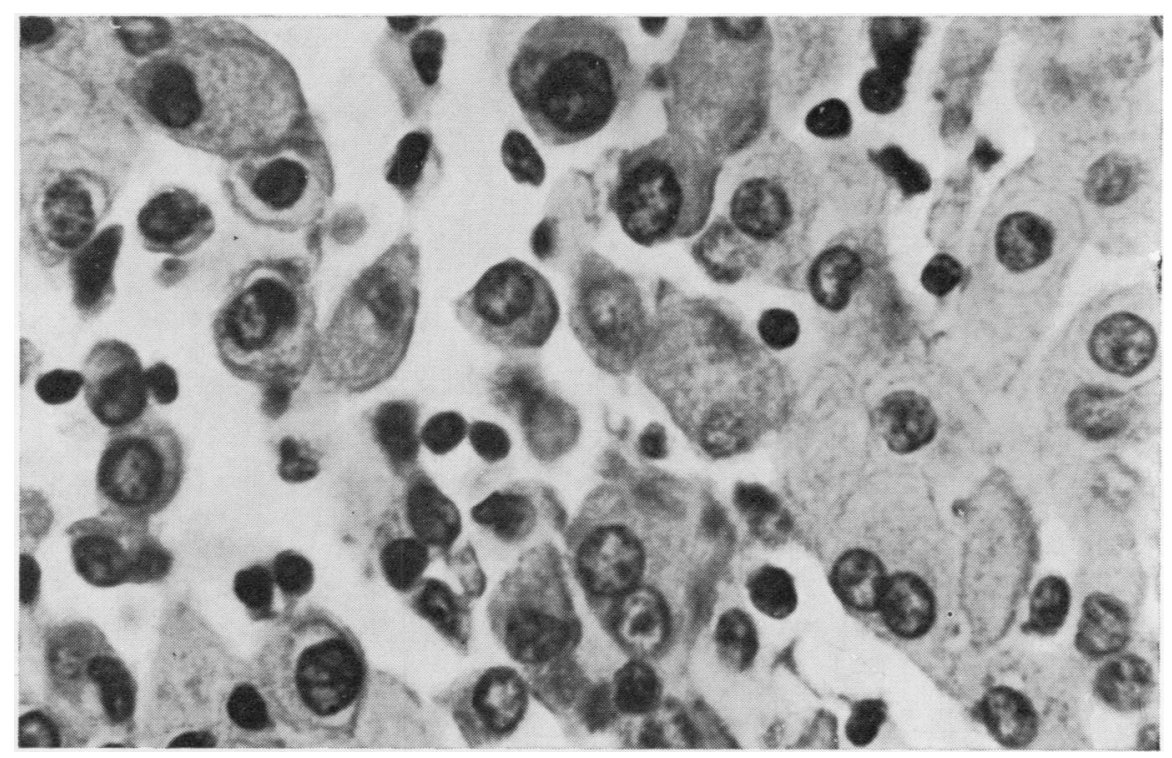

FIG. 6. Undifferentiated polygonal cell type, in solid sheets on right and as separate rounded cells on the left. Haematoxylin and eosin $\times 900$. 


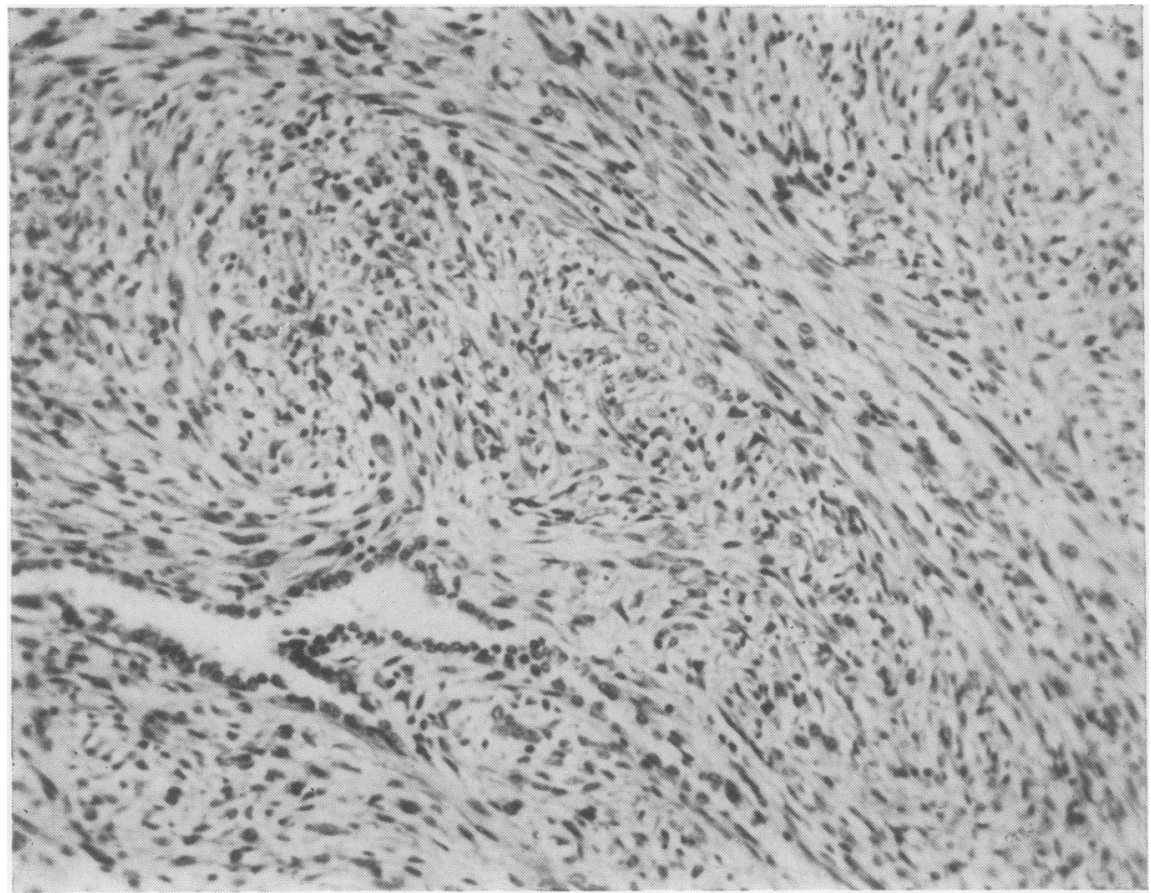

FIG. 7. Mixed type. Fasciculated fibrosarcoma area with scanty tubular inclusions.

Haematoxylin and eosin $\times 165$.

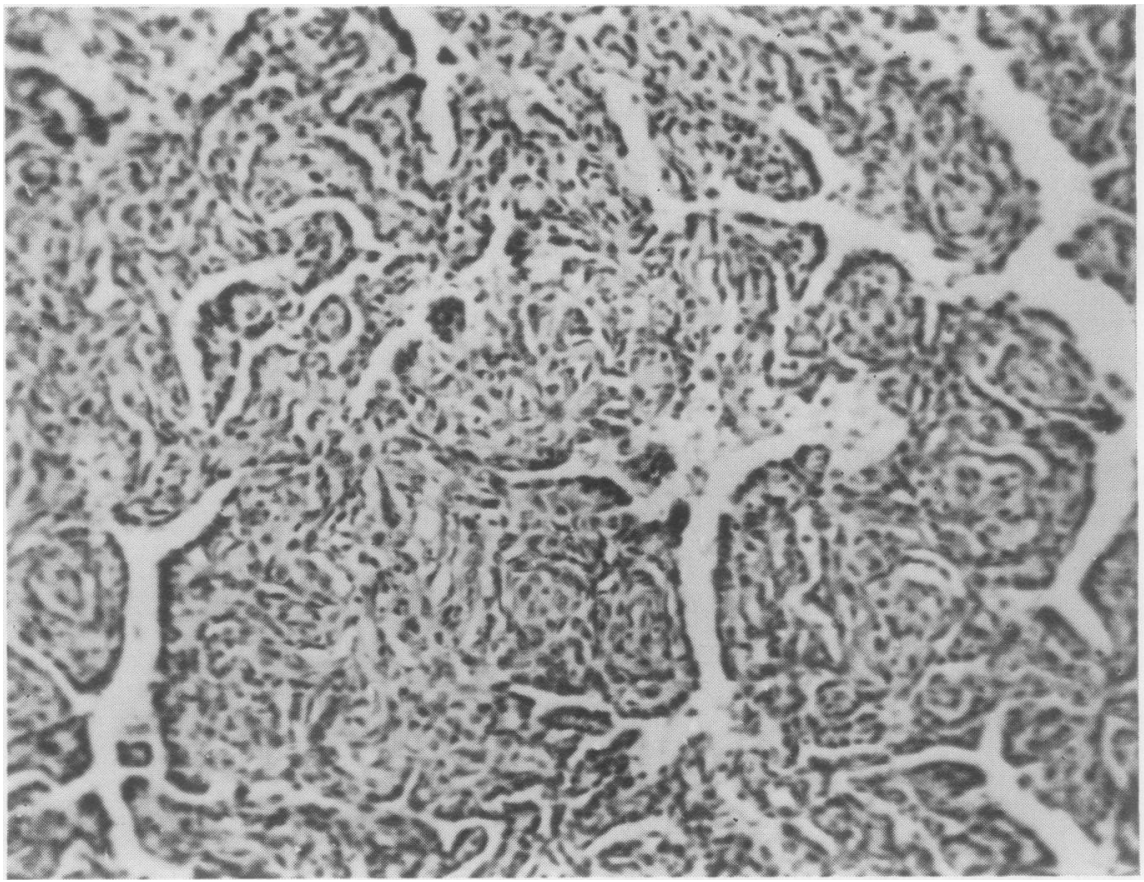

FIG. 8. Mixed type. An even mixture of tubulo-papillary and sarcomatous types. Haematoxylin and eosin $\times 165$. 
or to asbestos, and this should not be confused with a mixed tumour. Likewise, where a sarcomatous tumour invades peripheral lung through the pleura the encased alveoli become isolated glandular acini lined by cuboidal cells, which can be very like the appearance of a mixed tumour.

A primary carcinosarcoma of the lung can produce a rather similar appearance but frequently has a bronchial origin, and the carcinomatous element of the tumour is usually squamous. A tumour of almost indentical features is a malignant synovioma, but this is not likely to cause confusion.

\section{MORBID ANATOMY}

The appearances of the chest contents in cases of pleural mesothelioma have been well described and show little variation from case to case. The lung on the affected side shows compression collapse and sometimes bronchopneumonia and secondary tumours, and it is encased in a rubbery, thick, yellowish-grey tumour involving both visceral and parietal pleura, which may enclose cavities filled with necrotic or fibrinous material or glairy fluid. The tumour usually encases the whole lung, but when not so advanced it may be possible to identify pleural plaques. However, these are usually present and best seen on the parietal pleura of the opposite lung.

The tumour spreads into interlobar fissures and interlobular septa ; there is often direct spread to the pericardium and also, through the diaphragm and through the chest wall to subcutaneous tissues. Mediastinal and hilar lymph nodes are frequently affected, and there may be a diffuse posterior mediastinal spread with tumour encasing the aorta and oesophagus.

The following features were found in 32 necropsies.

PLEURA In five cases the pleural involvement was bilateral and of similar extent on both sides. In 14 cases the left side was predominantly or solely affected, and mesothelioma was found on the right side in 13 cases.

PERICARDIUM AND HEART The pericardium was involved by direct extension in 15 cases. This was found in 10 of the 14 cases in which only the left

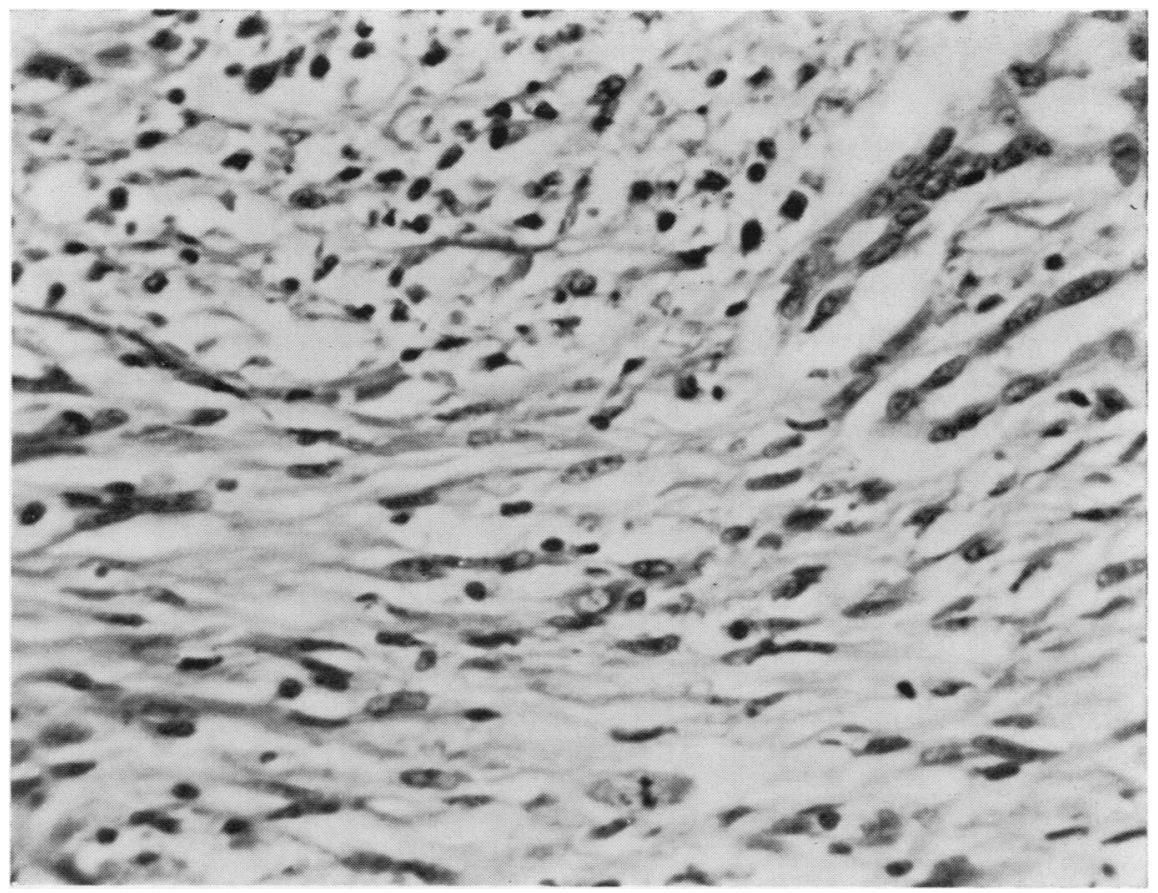

FIG. 9. Mixed type. Mainly sarcomatous but with two acini on the right side, and a mitosis in the sarcomatous tissue in the lower centre. Haematoxylin and eosin $\times 385$. 


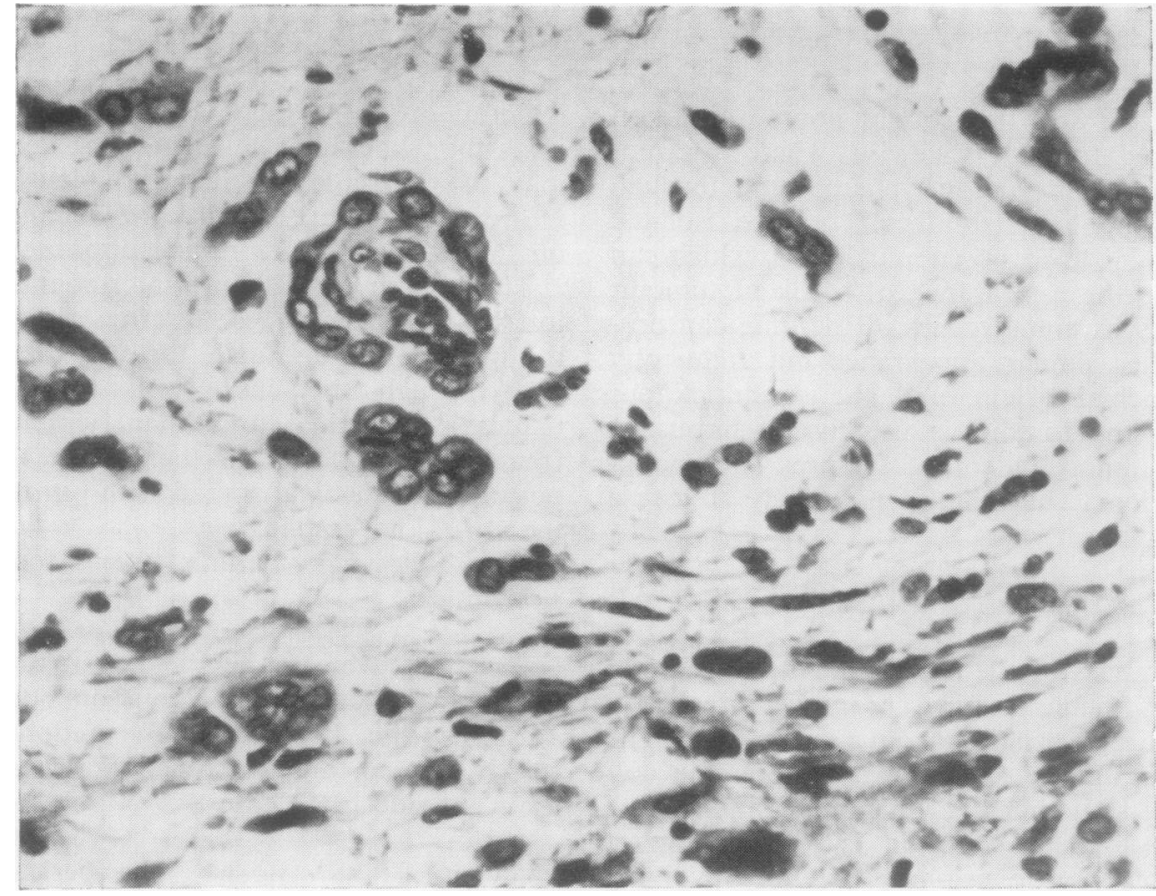

FIG. 1C. Mixed type. Myxomatous area with tumour cells attempting to form acini in the upper half, and looking sarcomatous in the lower half. Haematoxylin and eosin $\times 385$.

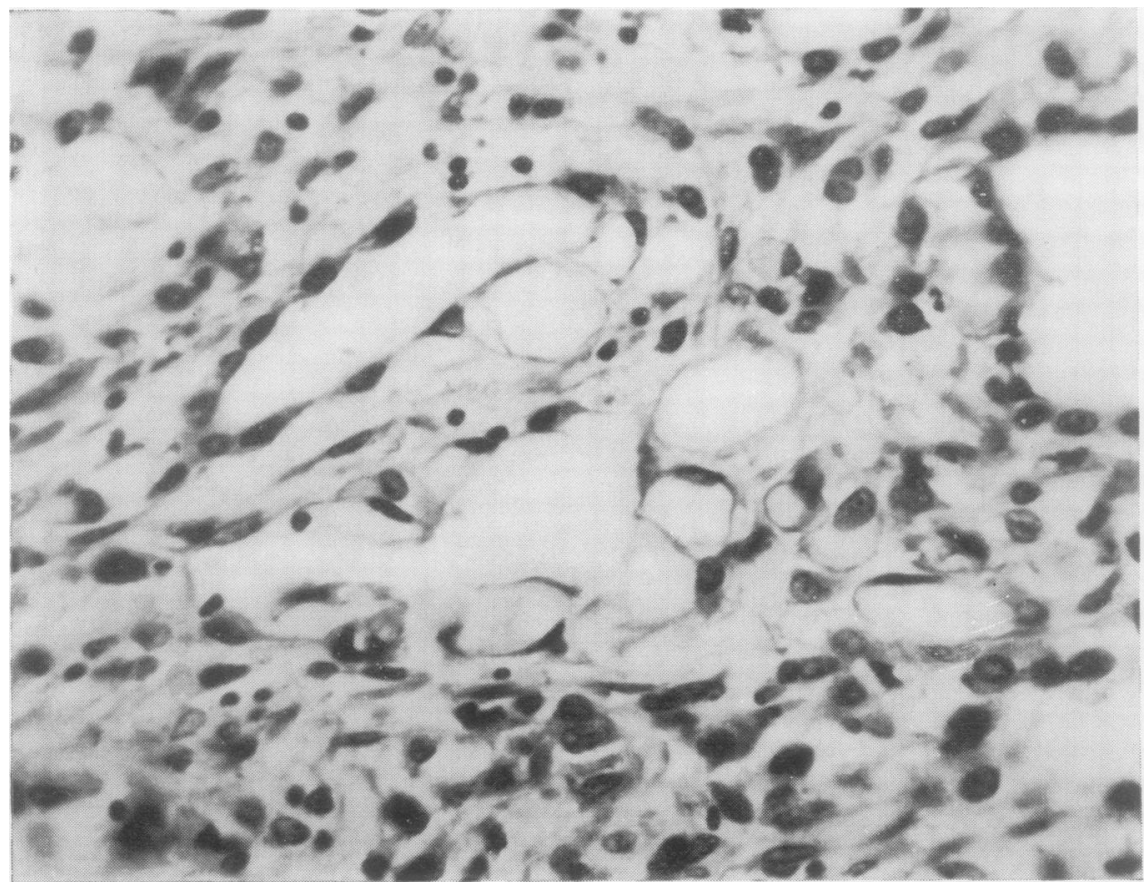

FIG. 11. Mixed type. Capillary appearance in acinar area. Haematoyxlin and eosin $\times 385$. 


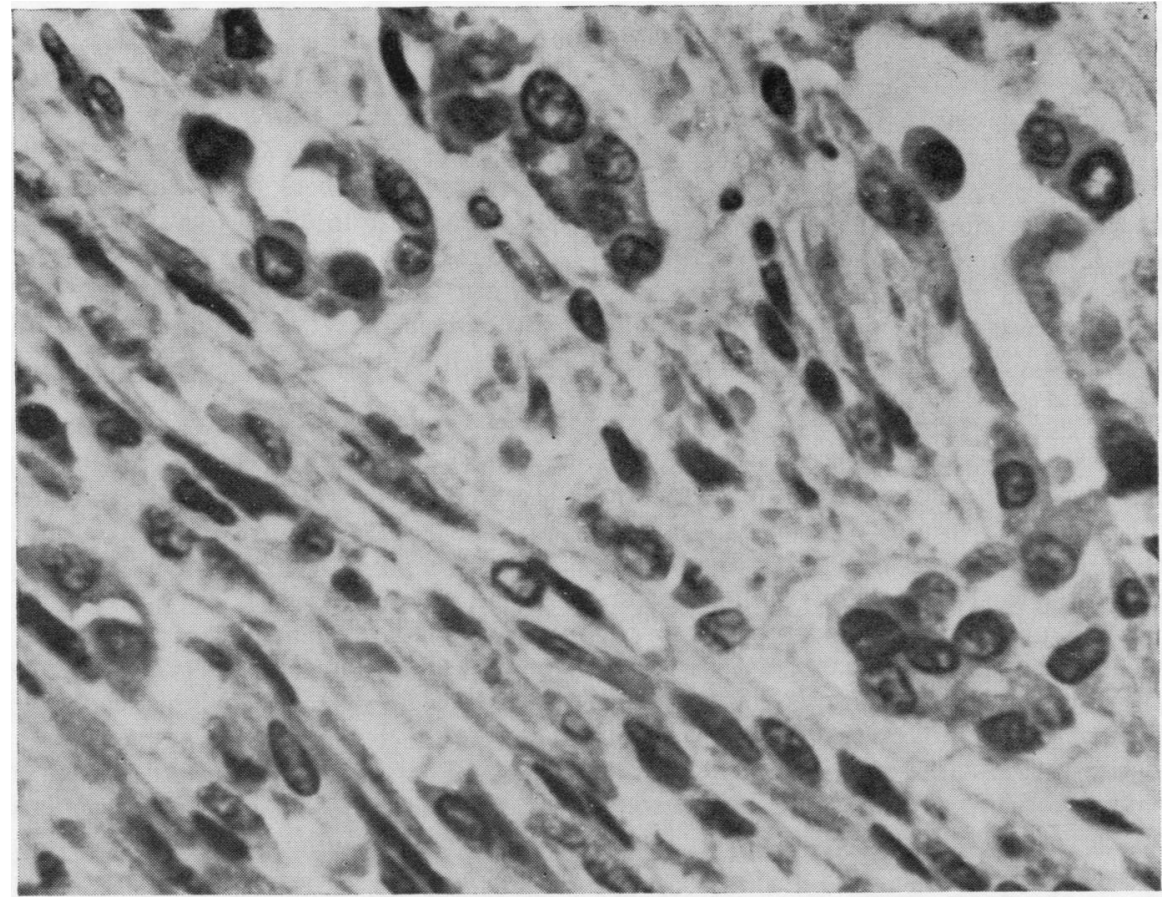

FIG. 12. Mixed type. Acinus formation in sarcomatous area. Haematoxylin and eosin $\times 785$.

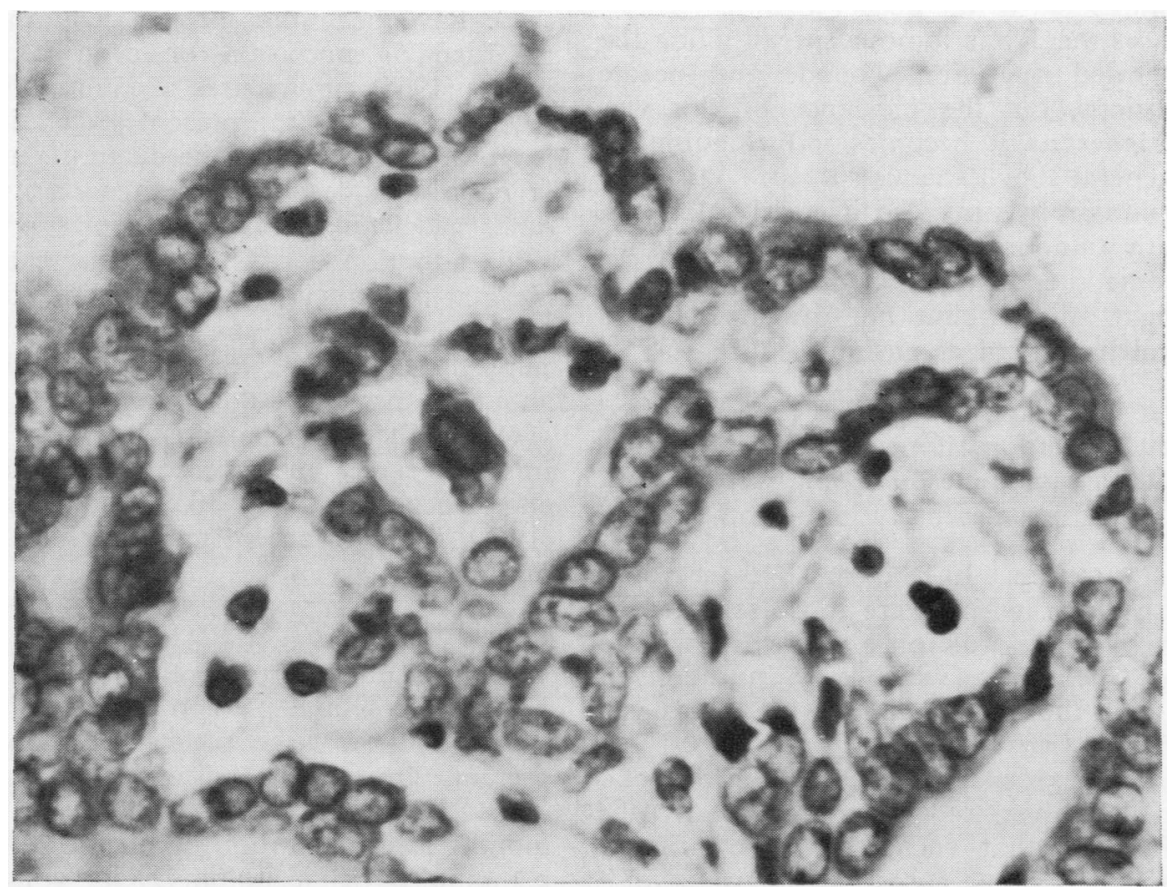

FIG. 13. Mixed type. Tumour deposit in hilar lymph node showing only tubulo-papillary pattern. Haematoxylin and eosin $\times 785$. 
pleura was affected, in only 3 of 13 cases in which only the right pleura was affected, and twice when pleural involvement was bilateral.

The heart was the site of tumour in 10 cases, always when the pericardium was also affected and usually by direct extension to the atria, but in three patients metastases were present in the ventricular myocardium. All histological types spread to the heart with equal facility.

LYMPH NODES In 14 cases hilar and mediastinal lymph nodes were replaced by tumour. Axillary, cervical, and abdominal nodes were each involved on three occasions, and an inguinal lymph node once. Heard (1966) has reported lymph node involvement to be uncommon, but in the present series it was found in $50 \%$ of cases.

It was noticeable that sarcomatous elements did not spread into lymph nodes though they often encased them, and the same applied to the sarcomatous elements of mixed tumours. This agrees with the findings of Hourihane (1964).

CHEST WALL, OPERATION SITE, AND DIAPHRAGM Direct extension of the tumour into the chest wall on the same side was present in all cases, with tumour eroding the ribs. In 11 cases there were subcutaneous tumour nodules on the outside of the chest wall fixed to the deeper tissues.

In six cases there was tumour spread along the track of healed operation wounds and needle biopsy incisions, but the incidence of this was probably higher as it becomes indistinguishable from the general subcutaneous spread.

The diaphragm was invaded in nearly all cases, usually with tumour appearing on the inferior surface, sometimes extending directly into the liver or right adrenal, but not often associated with general peritoneal extension.

PERITONEUM In two cases there was generalized involvement of the peritoneum and mesentery, and localized areas of mesothelioma were present in the peritoneum or mesentery in nine other cases.

DISTANT METASTASES In the first 10 necropsy cases in the series, which were those reported by Owen (1964), there was only one case with a blood-borne metastasis, which was in the liver. By contrast, in the next 22 necropsies, metastases were found in 14 cases.

The commonest sites for blood-borne metastases were the liver and the lung, usually the opposite lung to that encased by the primary growth, though in some cases there were secondaries in both lungs. There were also secondaries in the adrenals ( 3 cases), thyroid ( 2 cases), and kidney (1 case). Bony secondaries were present in $\stackrel{\overline{9}}{9}$ two cases, one in a lumbar vertebra and one in a right femoral neck. In one case there was a secondary tumour of the meninges in the right $\frac{\bar{m}}{\frac{D}{2}}$ middle cranial fossa. All histological types of $\stackrel{\mathbb{Q}}{\varrho}$ tumour gave rise to blood-borne metastases, but $\cong$ while over half the sarcomatous tumours did so, less than a quarter of the other types showed this spread.

This changed incidence of metastases in the $\mathscr{N}$ second part of the series reflects an increased $\vec{x}$ confidence in the diagnosis and nature of the ${ }_{i}^{x}$ tumour, and the more detailed study of the prospective cases in the series. Probably the retro- $\vec{\sigma}$ spective series was incomplete through non-윽 acceptance of metastasizing growths.

Although Godwin (1957) accepted extensive metastases in several of his cases without comment, later writers have been less willing to accept metastasizing tumours as mesotheliomas. McCaughey (1958) was rather guarded on the $\vec{\varphi}$ subject mentioning metastases to lung and liverbut regarding more distant spread as unusual, though not in itself a reason for changing the diagnosis. In other accounts (Churg, Rosen and Moolten, 1965; Hourihane, 1964; Payling Wright and Heard, 1966) the infrequence of distant meta- $\AA$ stases has been emphasized, so much so that when $\underset{\overrightarrow{7}}{\overrightarrow{7}}$ these have been present the diagnosis has been $\frac{0}{3}$ regarded as uncertain or even been rejected. Evans (1966) summarizes a commonly held view when he says 'at the present stage of our knowledge of these tumours the diagnosis in such cases $\vec{\sigma}$ is open to question since the distinction from other widely metastasizing neoplasms is difficult.$\stackrel{\times}{-}$ Wide adoption of this view has meant that only 3 . mesotheliomas with no or very limited metastases have been accepted as mesotheliomas in many $\frac{3}{3}$ published accounts, perpetuating a misconception 의 about the nature of the tumour.

Originally we shared the view that these $\frac{D}{0}$ tumours rarely metastasize, but with increasing experience we have, like Churg and Selikoff or (1968), come to accept metastases as of frequent $N$ occurrence.

\section{CLINICAL FEATURES}

The commonest presenting complaints were $\stackrel{0}{=}$ breathlessness and pain in the chest, and on first $ळ$ examination a large pleural effusion was often present. The most persistent symptom was pain, $\frac{0}{0}$ while dyspnoea was often relieved for several $\overrightarrow{\mathbb{D}}$ months after aspiration of pleural effusions. Less $\frac{\rho}{\mathbb{D}}$ common initial symptoms were cough and loss $\varrho$ of weight (8 patients), congestive cardiac failure ( 3 patients), and haemoptysis (1 patient). In 278 
case records there was comment about finger clubbing at the first examination. It was absent in 16 cases, doubtful in six, and definitely present in five cases.

AGE (FIG. 14) Apart from one mesothelioma in a boy aged 16 years, all the patients were between the ages of 40 and 82 years at the time they sought medical advice. Thirty-eight patients (74\%) were between the ages of 50 and 70 years, mean $60 \pm 10$ years SD.

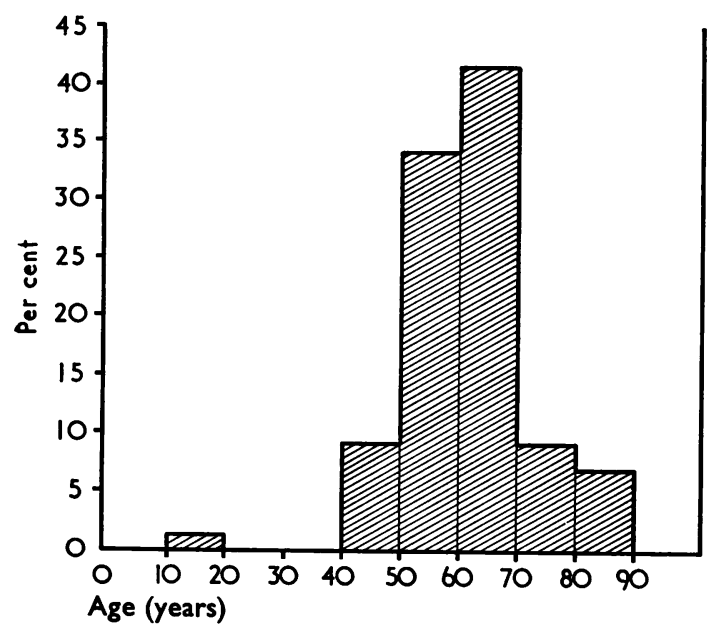

FIG. 14. Age distribution of 52 mesothelioma patients.

SEX Seventy-seven per cent of the patients were men, reflecting the fact that asbestos exposure on Merseyside is predominantly a male occupational hazard. In the few cases where no asbestos contact could be established from the patients' occupations the disease appeared to affect both sexes equally, but too few were involved to be significant.

DURATION OF ILLNESS In some patients it was not possible to date accurately the first onset of symptoms, either because the records were inadequate or because the symptoms were superimposed on those from pre-existing chronic bronchitis and emphysema. However, in 36 patients this was possible, and so the duration of illness from first symptoms until death was known, and is shown graphically in Fig. 15. Fifty-three per cent of patients survived one year, $33 \%$ survived two years, $17 \%$ were alive after three years, and $8 \%$ (three cases) lived over five years. These

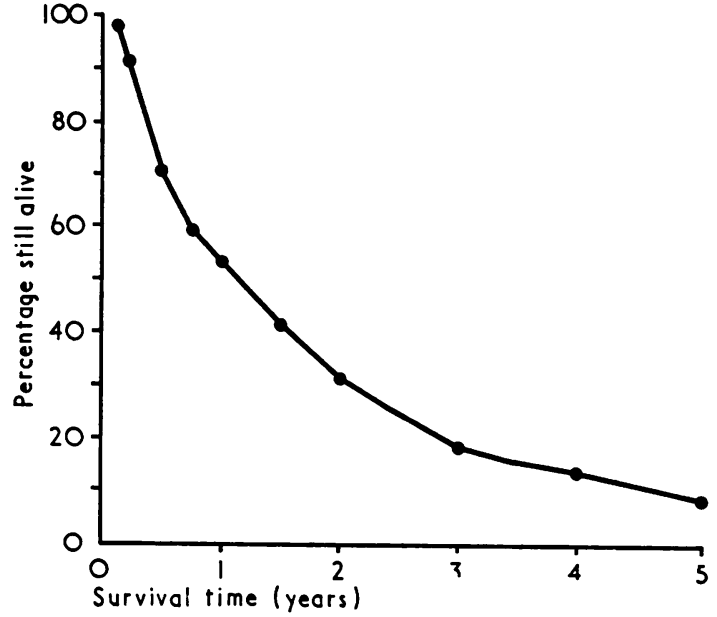

FIG. 15. Total duration of illness of 36 mesothelioma patients from first symptoms to death.

figures show less favourable results than might be expected in uncomplicated cases without surgical treatment, because two died from unrelated coronary thrombosis, one from a bleeding duodenal ulcer, and two from postoperative pulmonary embolism. There was no evidence that radical surgery or chemotherapy affected the prognosis favourably.

The relatively long survival with only slow deterioration of many mesothelioma patients has received little attention, except from Le Roux (1962). Hinson (1965) even says that death usually occurs within a year of the first symptoms. Because of this slow deterioration we find that clinicians caring for mesothelioma patients, but more familiar with cases of inoperable lung cancer, often ask for the surgical histology to be reviewed two or three years after the original report.

A direct comparison of the survivals of both inoperable lung cancer and pleural mesothelioma, from the time of histological diagnosis, has been made to illustrate this difference in survival (Fig. 16). The lung cancer patients were a series of 419 cases diagnosed by bronchial biopsy at Broadgreen Hospital during 1950-5 but considered to be inoperable (Whitwell, 1961). The mesotheliomas are the 30 in the present series diagnosed from operation specimens. The graph underestimates the mesothelioma survival because of the relatively higher early mortality after pleurectomy or decortication compared with bronchial biopsy, and because the mesothelioma group 


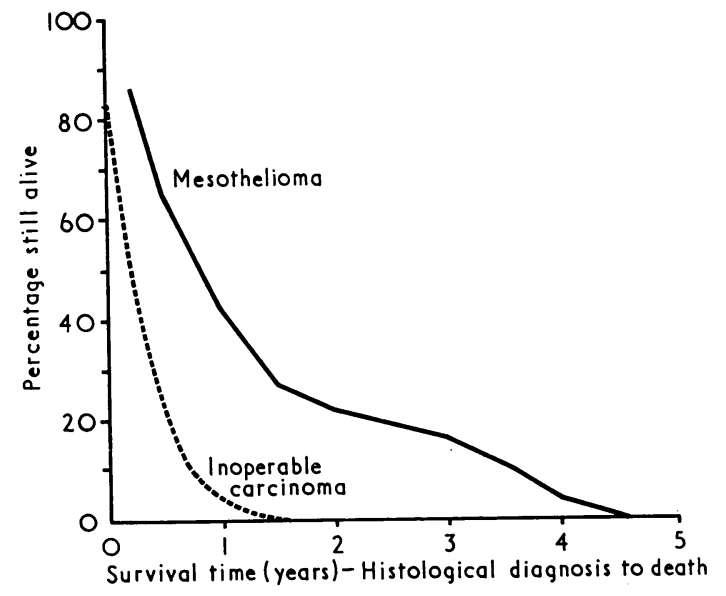

FIG. 16. Comparison of survival rates of bronchial carcinoma and pleural mesotheliomas from histological diagnosis to death.

includes five living patients who have been listed according to their present survivals of between 6 and 36 months.

At six months $20 \%$ of lung cancer patients and $66 \%$ of mesothelioma patients remained alive, while at 12 months only $4 \%$ of lung cancer patients remained alive but there were still $43 \%$ of the mesothelioma patients. All the lung cancer patients had died by 18 months, but $26 \%$ of the mesothelioma patients survived, and one of these survived over four years. This finding disagrees with that of Elmes (1966) who found that few patients survived more than a year from the time that the diagnosis had been established.

CIGARETTE SMOKING It has been suggested that a further factor in addition to asbestos is necessary for the development of mesothelioma, so the possible association of cigarette smoking and asbestos with mesothelioma has been considered in the present series.

The smoking habits of 28 patients had been recorded and included 10 non-smokers, eight who had smoked up to 10 cigarettes a day, and 10 who smoked more than this. The incubation period from first exposure to asbestos until development of tumour was no shorter in the smokers than in the non-smokers, neither was the duration of asbestos exposure any shorter in the smokers.

\section{INDUSTRIAL EXPOSURE TO ASBESTOS}

MALE PATIENTS Thirty-five of the 40 patients with mesotheliomas had experienced significant exposure to asbestos dust. In 28 cases this had been incurred through their trades in shipbuilding and repairing firms, and in three further cases with numerous asbestos bodies in the lungs the patients had spent a large part of their working lives in dock-side occupations. Only four patients in the series had been exposed to asbestos while following non-maritime occupations-two laggers, one asbestos factory worker, and one brake-lining factory employee.

The trades of the affected shipyard workers are given in the Table, showing that at least a dozen different occupations are at risk. Many of these workers had a vague knowledge of the hazards to health from asbestos but some denied any contact with asbestos though their lungs contained numerous asbestos bodies. It seems that the exact nature of their work was much less important than the fact that they all worked in shipyards. Elmes and his colleagues (1965) have graded the work of shipyard employees with mesotheliomas into that with heavy, light, and no asbestos risk, but Harries (1968) has shown from his work in Royal Naval dockyards that the risks of mesothelioma are not confined to those workmen who actually handle asbestos, and he mentions the trades of men with mesothelioma as boilermaker, fitter, labourer, shipwright, and welder.

T A B L E

SHIPYARD TRADES OF 28 PATIENTS WITH PLEURAL MESOTHELIOMA

\begin{tabular}{|c|c|c|c|c|c|}
\hline & & & & & No. of Patients \\
\hline 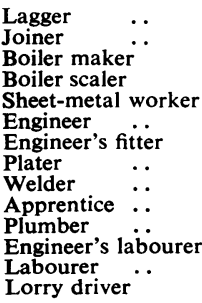 & $\begin{array}{l}\ldots \\
\cdots \\
\cdots \\
\cdots \\
\cdots \\
\cdots \\
\cdots \\
\cdots\end{array}$ & $\begin{array}{l}\ldots \\
\cdots \\
\cdots \\
\cdots \\
\cdots \\
\cdots \\
\cdots \\
\cdots \\
\cdots \\
\cdots\end{array}$ & $\begin{array}{l}\ldots \\
\cdots \\
\cdots \\
\cdots \\
\cdots \\
\cdots \\
\cdots \\
\cdots \\
\cdots \\
\cdots\end{array}$ & $\begin{array}{l}\ldots \\
\cdots \\
\cdots \\
\cdots \\
\cdots \\
\cdots \\
\ldots \\
\cdots \\
\cdots \\
\cdots \\
\cdots\end{array}$ & $\begin{array}{l}4 \\
3 \\
3 \\
2 \\
2 \\
2 \\
2 \\
2 \\
2 \\
2 \\
2 \\
2 \\
1 \\
1 \\
1 \\
1\end{array}$ \\
\hline
\end{tabular}

The five cases with no occupational history of asbestos exposure were a grocer, a chlorine plant $\stackrel{\bullet}{\circ}$ operator, a leather worker, an electrician, and a schoolboy. In no case was there any evidence of ${ }^{+}$ home or environmental exposure to asbestos. All $\frac{0}{3}$ died without necropsy studies except the leather $\frac{O}{D}$ worker, and no asbestos bodies were found in his $\stackrel{?}{\Phi}$ lungs. Though some electricians are exposed to $\varrho$ asbestos dust there was no history of asbestos? exposure in the electrician with the mesothelioma. 
FEMAle PATIENTS Among the 12 cases of mesothelioma were eight with a definite history of industrial asbestos dust exposure, and of the others two had no known hazard but had scanty asbestos bodies in the lungs, one had no hazard and no asbestos bodies in the lungs, and one with no hazard remains alive.

Of the eight patients with asbestos-induced mesotheliomas, three died without necropsy, in three necropsy studies showed moderate or numerous asbestos bodies in the lungs, and two are still alive.

Two of the eight asbestos-induced mesothelioma patients had been exposed to asbestos in asbestos factories before they moved to Merseyside. The other six, who are the only women to have suffered industrial exposure on Merseyside, had worked in various bag and sack repair works. These patients had been sorters or repairers of bags and sacks and they dealt with dusty used hessian sacks which had sometimes contained asbestos. Owen (1964) described the first two of these cases, drawing attention to this unusual occupational risk from asbestos: the only other mesothelioma patient of similar occupation we have found is one in the large series described by Newhouse and Thompson (1965) from London. Their case 76, described as a remaker of old sacks, was classified among those with no history of asbestos contact but clearly belongs in the same group. It is difficult to believe that this industry is either largely confined to Merseyside or that sacks for repair in other parts of the world are more free of asbestos dust, so it is likely that many further cases from this occupation will be found.

The four non-industrial mesotheliomas occurred in a housewife who had always lived in a small village in the Isle of Man, a grocery assistant, a brewery worker who only worked in the bottlelabelling plant, and a football-pool checker who had worked on gun drilling during the war. Two of these showed scanty asbestos bodies in the lungs but no more than is likely to be found occasionally in the adult female population.

DURATION OF EXPOSURE The total time spent in a shipyard, asbestos factory, brake-lining factory, or sack repair factory has been regarded as the period of exposure, even though some patients had in their later years been promoted to supervisory posts and escaped rather too late from the asbestos dust.

The period of exposure to asbestos dust of 36 patients is known and shows a very wide range, from four patients with only three years' exposure to four patients with over 50 years' exposure. The four patients with short exposures were questioned closely about their other jobs but none seemed relevant, and although these patients had ceased to be exposed to asbestos over 20 years before developing their mesotheliomas, the three who died showed asbestos bodies in their lungs.

The mean exposure period of the series is $28 \pm$ 16 years SD, rather shorter than the mean of 35 years found in the Belfast shipyards (Elmes et al., 1965). There was no significant difference in duration of exposure between one hazardous trade and another, or between men and women.

INTERVAL BETWEEN FIRST ASBESTOS EXPOSURE AND FIRST MESOTHELIOMA SYMPTOMS The date of onset of mesothelioma symptoms and the exact period of asbestos exposure were known in 33 patients and are shown for the shipyard and sackware workers (Fig. 17). The interval from first exposure to asbestos until first mesothelioma symptoms is a much less variable figure than that for total asbestos exposure.

Apart from two short periods of 13 years and 19 years the interval was always over 25 years, and in 11 patients was over 50 years. The mean value of this interval for the 33 cases was $42 \pm$ 12 years $\mathrm{SD}$, which is surprisingly close to the Belfast figure of $43 \pm 13$ years SD for the slightly different interval between first asbestos exposure and death (Elmes, 1966). As the minimum exposure period in the series was three years it is likely that the induction period of an asbestosinduced mesothelioma is about $\mathbf{4 0}$ years.

LUNG CHANGES IN ASBESTOS-INDUCED PLEURAL MESOTHELIOMAS Lungs from 30 mesothelioma patients who had a history of asbestos exposure were examined at necropsy and asbestos bodies were found in all of them. However, as these bodies have been found recently in a high proportion of urban male lungs and in a slightly lower proportion of urban female lungs, their presence does not itself imply excessive or industrial exposure to asbestos.

The most certain evidence of excessive asbestos exposure is the presence of asbestosis, and basal asbestosis was present in five cases (17\%). These were three laggers, a shipyard labourer, and a boilermaker. In 10 other cases asbestos bodies were so numerous that they were immediately seen, often in clumps, in routine sections. In 15 cases more prolonged search was required to find asbestos bodies. 


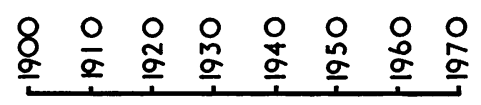

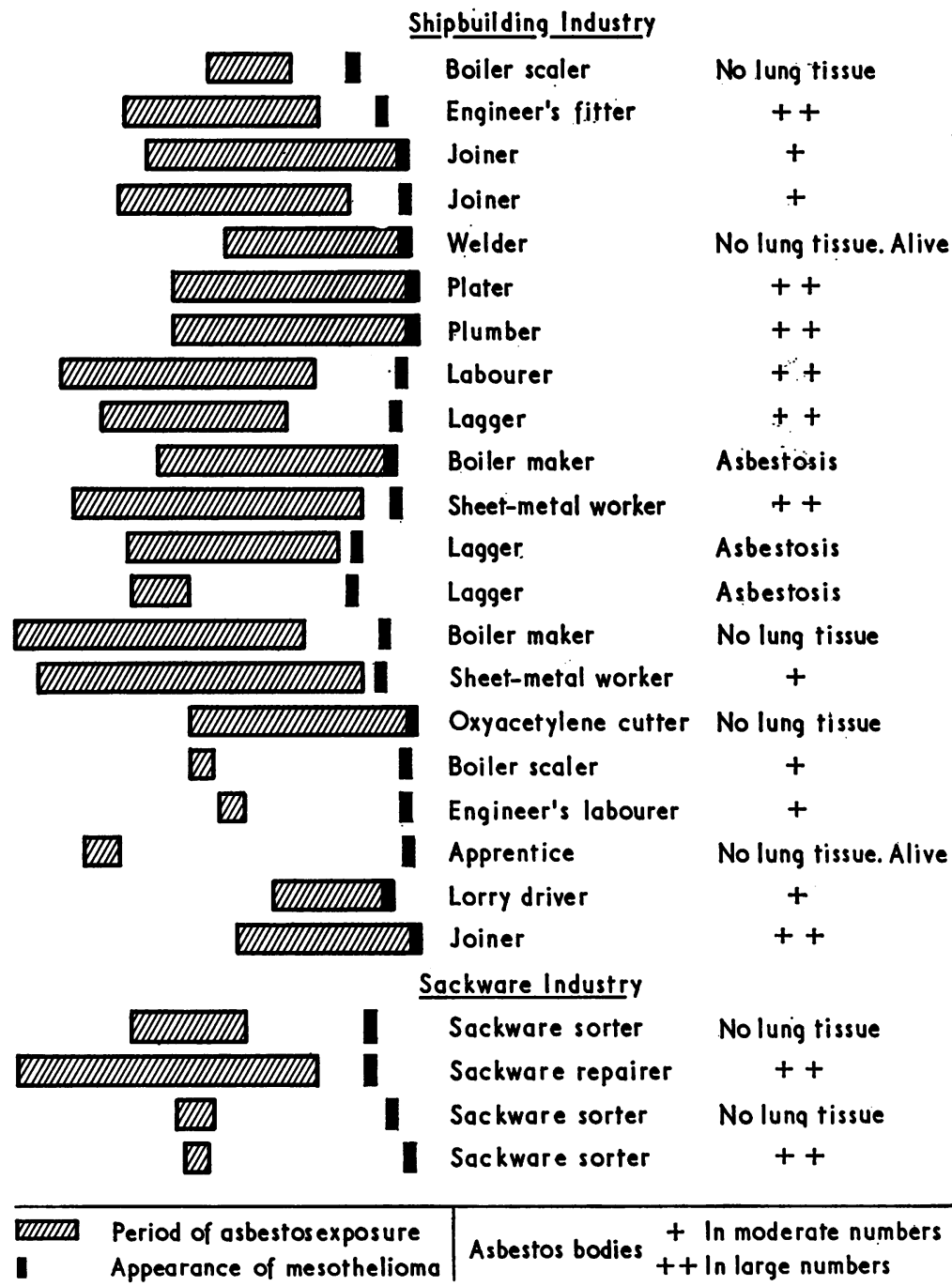

FIG. 17. Time relationship of industrial exposure to asbestos with the development of mesothelioma and the state of the lungs.

LUNG SMEARS In 1966-7 lung smears were examined routinely at Broadgreen Hospital from 200 consecutive necropsies on patients of both sexes over the age of 30 years, excluding any known cases of pneumoconiosis. Asbestos bodies were present in $24 \%$ of the series, in $33 \%$ of men and in $13 \%$ of women. The most strongly positive group of men between 50 and 70 years of age, of whom 39\% showed asbestos bodies. But the number of asbestos bodies in these patients was nearly always far less than is found after indus- $Q$ trial exposure. Of the 48 positive smears, $41(85 \%)$ showed less than 12 bodies per smear, and only? seven patients showed between 25 and 50 bodies per smear. These seven may well have been exposed to asbestos in industry, for they were all elderly men with few occupational notes, except $\stackrel{\mathbb{Q}}{\stackrel{Q}{\mathscr{C}}}$ that two had worked as painters for industrial $\overline{0}$ 
firms, one was a wood machinist, and one had worked in a shipyard.

Lung juice smears made on the asbestosinduced mesothelioma patients' lungs have been examined quantitatively in the last 14 necropsy cases, which did not include any showing asbestosis. Only one case showed less than 11 asbestos bodies per smear, and he had been a boiler scaler between 1929 and 1932 and afterwards a grocer. Five cases showed between 12 and 24 asbestos bodies per smear, and in eight cases there were between 25 and over 1,000 asbestos bodies per smear. We think that when asbestosis is absent, lung juice asbestos body smear counts can be of considerable value in differentiating industrial from urban asbestos exposure.

The distinction between an asbestos body and a pseudo-asbestos body is made easily from the nature of its central substance, which is transparent in the true body and usually black due to carbon in the pseudo-body. The only structures resembling the true asbestos body likely to be found is a talc body, which is much shorter. Of the 200 postmortem smears examined at Broadgreen Hospital $12 \%$ showed pseudo-asbestos bodies, but whereas $25 \%$ of the smears containing asbestos bodies also contained pseudoasbestos bodies, these were present in only $8 \%$ of the smears without asbestos bodies. Pseudoasbestos bodies were also sometimes found with asbestos bodies in smears from mesothelioma cases.

\section{AUTHENTICITY OF PRIMARY PLEURAL MESOTHELIOMA}

The argument as to whether primary pleural mesotheliomas exist or are nearly always secondary tumours appears to have been settled in the last 10 years in favour of accepting them as primary growths with only a few abstentions. From our study we certainly accept asbestos-induced mesotheliomas as primary neoplasms but make this qualified acceptance because only very rarely have non-industrial mesotheliomas been subjected to adequate study. Of our nine patients with nonindustrial mesotheliomas, all have died, but only three necropsies were carried out, confirming one sarcomatous and two tubulo-papillary mesotheliomas. The six other cases were all tubulopapillary tumours, but three were atypical in that the histology showed faint positive mucicarmine staining in the tumour cells and acini, features rarely seen in asbestos-induced mesotheliomas. which raises slight doubt about the exactness of the diagnosis, which was based on a small amount of pleural tissue.
Even if all these nine cases are acceptable as mesotheliomas, the non-asbestos-induced mesothelioma remains a very rare tumour, which has appeared in our three hospitals about once in two years.

In this country the most persistent opposer to the existence of the pleural mesothelioma has long been Willis (1952), who gives personal experience and quotes previously published papers on the subject (the latest being from 1935 and 1942) in which he finds valid reasons for non-acceptance of the diagnosis. It is interesting that this work occurred in the first half of the century and is really a criticism against the existence of a nonasbestos-induced mesothelioma. With the widespread use of asbestos starting only at the beginning of this century, and a mean tumour induction period of around 40 years, there can have been only very few asbestos-induced mesotheliomas in the world at that period. In his later work Willis (1967) criticized many of the writers quoted in the present paper, largely on the basis of inadequate documentation or illustration of cases or lack of necropsy studies. He suggested that the diagnosis of mesothelioma should be made only after full postmortem examination, including the fine slicing of fixed lungs to search for small subpleural carcinomas. In the present series no fine slicing was necessary to see subpleural tumours, but these were metastases from the primary growths. If the majority of mesotheliomas were accepted as secondary carcinomas it would be impossible to explain their curious occupational incidence, their prolonged survival compared with accepted bronchial carcinomas, or their consistent macroscopic appearance, which is not typical of carcinoma.

\section{INCREASING INCIDENCE OF ASBESTOS-INDUCED PLEURAL MESOTHELIOMA}

Between 1955 and 1963 Owen (1964) found 12 histologically confirmed asbestos-induced mesotheliomas, and in the same hospitals between 1964 and 1970 we have found 31 additional cases. The pathology records at Broadgreen Hospital show that two cases occurred between 1950 and 1954: these figures suggest to us that there is a real and large increase in the incidence of this tumour.

Even after working on this subject for a long time it is difficult to become adapted to the amazingly long induction period shown by some of the patients. Several of the shipyard workers examined in the last five years first inhaled asbestos when building ships which fought at the battle of Jut- 
land, while their younger mates with mesotheliomas first contacted asbestos while building ships for the second world war. Our successors will, in about 40 years time, be seeing mesothelioma patients who first inhaled asbestos while building post-war nuclear submarines.

Even if advice contained in the white paper 'Problems Arising from the Use of Asbestos' (1967) is adopted by industry without delay, it will be some time in the twenty-first century before the incidence of pleural mesothelioma ceases to rise.

We wish to thank Dr. W. Glyn Owen for the use of his valuable notes, not only on the cases in the series that he published but also on a few of the later cases. We are grateful to our colleagues at Broadgreen, Aintree, and St. Catherine's Hospitals for making available the records of their patients, in particular Dr. D. L. Caldwell, of St. Catherine's Hospital, under whom were admitted most of the shipyard patients, and Dr. P. J. Taylor, of Aintree Hospital, who carried out several of the postmortem examinations. We are also indebted to Mr. A. Robertson and Miss J. Scott for histological preparations and for performing numerous asbestos body counts on lung smears.

\section{REFERENCES}

Ashcroft, T. (1968). Asbestos bodies in routine necropsies on Tyneside. Brit. med. J., 1, 614.

Churg, J., Rosen, S. H., and Moolten, S. (1965). Histological characteristics of mesothelioma associated with asbestos. Ann. N.Y. Acad. Sci., 132, 614.

and Selikoff, I. J. (1968). Geographic pathology of pleural mesothelioma. In The Lung. International Academy of Pathology Monograph, p. 284. Edited by A. A. Liebow and D. E. Smith. Williams and Williams, Baltimore.

Elmes, P. C. (1966). The epidemiology and clinical features of asbestosis and related diseases. Postgrad. med. J., 42, 623 .

McCaughey, W. T. E., and Wade, O. L. (1965). Diffuse mesothelioma of the pleura and asbestos. Brit. med. J., $1,350$.
Enticknap, J. B., and Smither, W. J. (1964). Peritoneal tumours in asbestosis. Brit. J. industr. Med., 21, 20.

Evans, R. Winston (1966). Histological Appearances of Tumours, 2nd ed., p. 118. Livingstone, Edinburgh and London.

Godwin, M. C. (1957). Diffuse mesotheliomas, with comment on their relation to localized fibrous mesotheliomas. Cancer (Philad.), 10, 298.

Harries, P. G. (1968). Asbestos hazards in Naval Dockyards. Ann. occup. Hyg., 11, 135.

Heard, B. E. (1966). Asbestosis. In Recent Advances in Pathology, 8th ed. Edited by C. V. Harrison, p. 366. Churchill, London.

Hinson, K. F. W. (1965). Cancer of the lungs and other diseases after exposure to asbestos dust. Brit. J. Dis. I Chest, 59, 121.

Hourihane, D. O'B. (1964). The pathology of mesotheliomata and an analysis of their association with asbestos exposure. Thorax, 19, 268.

Le Roux, B. T. (1962). Pleural tumours. Thorax, 17, 111.

McCaughey, W. T. E. (1958). Primary tumours of the pleura. J. Path. Bact., 76, 517.

Newhouse, M. L., and Thompson, H. (1965). Mesothelioma of pleura and peritoneum following exposure to asbestos in the London area. Brit. J. industr. Med., 22, 261.

Owen, W. Glyn (1964). Diffuse mesothelioma and exposure to asbestos dust in the Merseyside area. Brit. med. J., 2, 214.

Problems Arising from the Use of Asbestos. (1967). H.M.S.O., London.

Roberts, G. Hefin (1967). Asbestos bodies in lungs at necropsy. J. clin. Path., 20, 570.

Wagner, J. C., Munday, D. E., and Harington, J. S. (1962). Histochemical demonstration of hyaluronic acid in pleural mesotheliomas. J. Path. Bact., 84, 73. Sleggs, C. A., and Marchand, P. (1960). Diffuse pleural mesothelioma and asbestos exposure in the North Western Cape Province. Brit. J. industr. Med., 17, 260.

Whitwell, F. (1961). The histopathology of lung cancer in ? Liverpool: the specificity of the histological cell types of lung cancer. Brit. J. Cancer, 15, 440.

Willis, R. A. (1952). The Spread of Tumours in the Human Body, 2nd ed., p. 55. Butterworths, London. (1967). Pathology of Tumours, 4th ed., p. 181. Butterworths, London.

Wright, Payling G., and Heard, B. E. (1966). In Systemic Pathology, by G. Payling Wright, and W. St. C. Đ Symmers, vol. 1, p. 426. Longmans, London. 